\title{
Use of fluorescent optical fibre probe for recording parameters of brain metabolism in rat model
}

Olga Stelmashchuk, Evgeniya Seryogina, Gennadii Piavchenko, Alexander Alekseyev, Evgeny Zherebtsov, et al.

Olga Stelmashchuk, Evgeniya Seryogina, Gennadii Piavchenko, Alexander Alekseyev, Evgeny Zherebtsov, Andrey Dunaev, Evgeny Vorobyev, Alyona Kuznetsova, Elena Kuznetsova, Edik Rafailov, llya Rafailov, "Use of fluorescent optical fibre probe for recording parameters of brain metabolism in rat model," Proc. SPIE 10685, Biophotonics: Photonic Solutions for Better Health Care VI, 106854R (17 May 2018); doi: 10.1117/12.2290317 


\title{
Use of fluorescent optical fibre probe for recording parameters of brain metabolism in rat model
}

\author{
Olga Stelmashchuk ${ }^{\mathrm{a}, \mathrm{b}}$, Evgeniya Seryogina ${ }^{\mathrm{a}}$, Gennadii Piavchenko ${ }^{\mathrm{c}, \mathrm{d}}$, Alexander Alekseyev ${ }^{\mathrm{c}, \mathrm{e}}$, \\ Evgeny Zherebtsov ${ }^{\mathrm{f}}$, Andrey Dunaev ${ }^{\mathrm{a}}$, Ilya Rafailov ${ }^{\mathrm{g}}$, Evgeny Vorobyev ${ }^{\mathrm{b}}$, Alyona Kuznetsova ${ }^{\mathrm{b}}$, \\ Elena Kuznetsova ${ }^{\text {b }}$, Edik Rafailov ${ }^{\mathrm{f}}$
}

a Research and Development Center of Biomedical Photonics, Orel State University named after I.S. Turgenev, 95

Komsomolskaya St., Orel, Russia 302026

b Department of Industrial Chemistry and Biotechnology, Institute of Natural Sciences and Biotechnology, Orel State

University named after I.S. Turgenev, 95 Komsomolskaya St., Orel, Russia 302026

c Department of Histology, Cytology and Embryology, Medical Institute, Orel State University named after I.S.

Turgenev, 95 Komsomolskaya St., Orel, Russia 302026

d Pharmaceutical Research and Production Enterprise, JSCJ "Retinoids"

e Department of Anatomy, Operative Surgery and Emergency Medicine, Medical Institute, Orel State University named after I.S. Turgenev, 95 Komsomolskaya St., Orel, Russia 302026

f Aston Institute of Photonic Technologies, School of Engineering and Applied Science, Aston University, Aston

Triangle, Birmingham, UK B4 7ET;

g Aston Medical Technology Ltd., e4f, Faraday Wharf, Innovation Birmingham Campus, Holt Street, Birmingham, UK, B7 4BB

\begin{abstract}
This studiy was carried out on groups of clinically healthy male Wistar rats. Animals received distilled drinking water ad libitum for 1 month, water containing succinic acid, water containing zinc sulphate and succinate zinc. Using the method of fluorescence spectroscopy, the parameters of brain metabolism in vivo in a model of laboratory rats was investigated. Based on data obtained by fluorescence spectroscopy, we have registered a change in the degree of cellular respiration in different structures of the cerebral cortex with the toxic effect of zinc compounds and succinic acid on the oxygen exchange process.
\end{abstract}

Keywords: zinc compounds, succinic acid, zinc sulphate, brain metabolism, fluorescence spectroscopy, blood microcirculation, optical measurements in vivo, neurodegenerative diseases

*Olya.zh93@gmail.com; phone 791926979 92; www.bmecenter.ru/en/vascular-control

\section{INTRODUCTION}

Changes in metabolism in the structures of the brain are noted in many neurodegenerative diseases, generally in old age. Neurodegenerative diseases are a group of slowly progressing pathological states of the nervous system. They are characterised by the death of nerve cells, which leads to the development of specific neurological symptoms. This can occur at different ages but is mainly observed in older people.

It is a well-known fact that disruption of metabolic processes in brain structures are observed long before clinical manifestations. That is why the development of evaluation methods for metabolic disturbances in the brain presents itself as a real problem in fundamental medicine. The free form of zinc $(\mathrm{Zn} 2+)$ in the brain is present in the synaptic vesicles on the terminals of the glutamatergic nerves and is synaptically released during the activity of the neurons. Zn2+ is also associated with metalloproteins and is intracellularly mobilised under oxidative stress. $\mathrm{Zn} 2+$ plays a dynamic role in the physiology and the pathophysiology of brain function.

According to literature ${ }^{1,2}$, an increase in the concentration of zinc compounds can trigger a pathogenic molecular process leading to the development of neurodegenerative diseases of the central nervous system ${ }^{3,4}$. Also, exceeding the concentration of zinc in the body can cause disturbances in immune functions and provoke a shortage of chemical compounds, including iron or copper. Excess of zinc compounds for a long period can lead to the emergence of degenerative processes in the pancreas, liver ${ }^{5}$ and organs of the gastrointestinal tract.

At the same time, antioxidant therapy with succinic $\mathrm{acid}^{4}$ is capable of providing a neuroprotective effect in the development of neurodegenerative diseases. Succinic acid is an endogenous intracellular metabolite of the Krebs cycle 
that performs a catalytic function. This acid increases the rate of reactions and stimulates the formation of ATP. Moreover, there is an antihypoxic effect of succinic acid due to an increase in the concentration of GABA in the brain tissue. Succinic acid helps to regulate cellular metabolism in pathological conditions, accompanied by oxidative stress.

Also, the effect on brain tissues of small doses of a zinc succinate compound during its long intake into the organism is of particular interest.

One of the promising directions for studying the parameters of brain metabolism in vivo in a model of laboratory rats, is the recording of the spectrum by fluorescence spectroscopy ${ }^{6-8}$. This method is based on the excitation of the endogenous and exogenous fluorophores of biological tissue and registration of their fluorescence ${ }^{9}$. The method of fluorescence spectroscopy also has a high sensitivity and makes it possible to estimate the intensity of metabolic processes ${ }^{10}$, the state of oxygen metabolism of tissues and the distribution of fluorescent nanoparticles within the body ${ }^{11}$.

This study aims to obtain the results of changes in metabolic processes in the cerebral cortex of rats in vivo under conditions of introduction of zinc sulphate, succinic acid and succinate in the drinking water.

\section{MATERIAL AND METHODS}

Experimental studies were performed on clinically healthy male Wistar rats at the age of 5 months ${ }^{12}(\mathrm{n}=6$ in the group). Rats were obtained from the FSBI SCBT FMBA of. Russia ("Andreevka" branch). Before the transfer of the animals to the clean zone of the vivarium and the beginning of the experiment, the animals were kept in quarantine for 14 days. When placed in quarantine, the veterinarian conducted a primary assessment of the animals' condition . Immediately before the transfer to a clean zone and the formation of experimental groups, the veterinarian conducted a clinical examination of the animals. In the study, animals were selected with no signs of health related abnormalities, so that the average body weight did not differ statistically between the groups. Each animal was assigned an individual number. The basic rules of maintenance and care corresponded to the standards set out in the sanitary rules for the arrangement, equipment and maintenance of experimental biological clinics (Vivarii) and the position-guidance "Laboratory animals". All procedures for routine animal care were carried out by the SOP of the CJSC "Retinoids".

Animals received distilled drinking water ad libitum for 1 month (group 1), water containing succinic acid at a dose of $25 \mathrm{mg}$ per litre (group 2), water containing zinc sulphate at a dose of $3 \mathrm{mg}$ per litre (group 3) and zinc succinate in a dose of $100 \mathrm{mg}$ per litre (group 4). The manifestation and severity of pathological features were evaluated according to the corresponding standard procedure.

For the detection of fluorescence signals, excitation at $365 \mathrm{~nm}$ and $450 \mathrm{~nm}$ was used, which corresponds to the excitation wavelengths of the NADH and FAD. The fluorescence spectroscopy system with fibre-optical probe "LAKK-M" (SPE "LAZMA" Ltd, Russia) was used for the in vivo measurements (fig.1 a). The system provides multiwavelength excitation, detects emission, and processes the fluorescence signal. Its light sources include fluorescence excitation in UV (wavelength $=365 \mathrm{~nm}$, power $=1.5 \mathrm{~mW}$ ), blue (wavelength $=450 \mathrm{~nm}$, power $=3.5 \mathrm{~mW}$ ) and green light (wavelength $=532 \mathrm{~nm}$, power $=4.5 \mathrm{~mW}$ ). The abovementioned fluorescence excitation powers are provided at the tip of fibre probe, which induces an excitation light flux in the tissue of no more than $0.16 \mathrm{~W} \mathrm{~m}-2$ for $365 \mathrm{~nm}$ and $0.37 \mathrm{~W} \mathrm{~m}-2$ for $450 \mathrm{~nm}$. The spectrometer was a polychromator with a diffraction grating, and a CCD (TCD1304AP, Toshiba, Tokyo, Japan) was used as the detector.

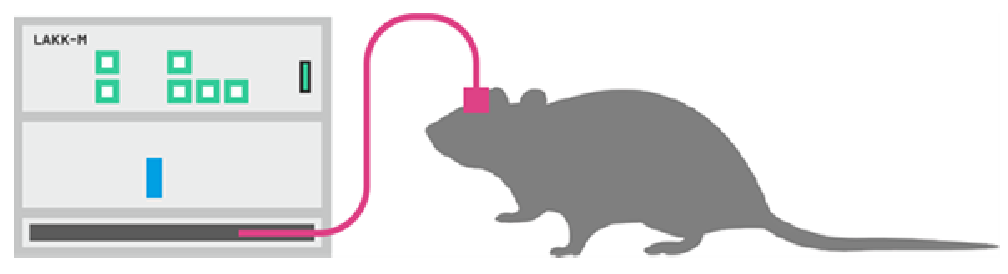

(a)

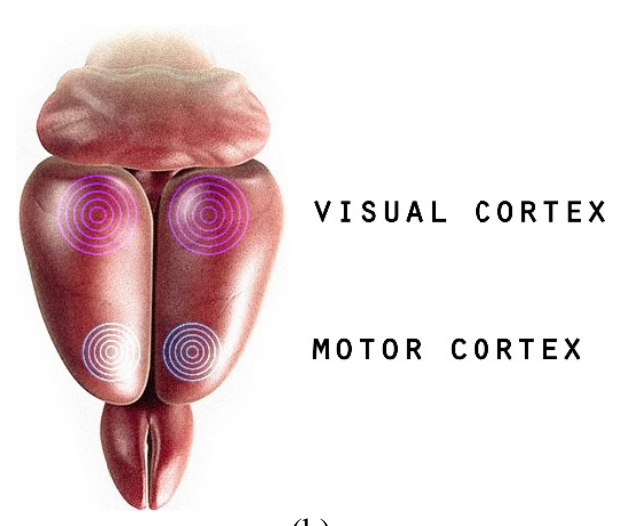

(b)

Figure 1. Experimental equipment: scheme of the "LAKK-M" device (a) and the areas of cortex observation (b) 
The zones of the motor and visual cortex of rat brain were chosen ${ }^{15}$. Around 10 signals per region were recorded from the "LAKK-M" device on the surface of the cerebral cortex for each hemisphere, at an interval of 5-10 seconds. (fig 1).

\section{EXPERIMENTAL RESULTS AND DISCUSSION}

This choice of the excitation wavelengths is based on the fact that in probing biological tissue by UV light (e.g. $365 \mathrm{~nm}$ ) the endogenous NADH fluorescence excitation is observed in the range $490-510 \mathrm{~nm}^{13}$. When excited with blue light (e.g., $430-450 \mathrm{~nm}$ ) fluorescence flavins are recorded in the range of about $510-520 \mathrm{~nm}^{14}$. The recorded spectra from each hemisphere were averaged for each group of animals. Then, a comparison was made of the maximum fluorescence intensity parameter at selected wavelengths in the groups.

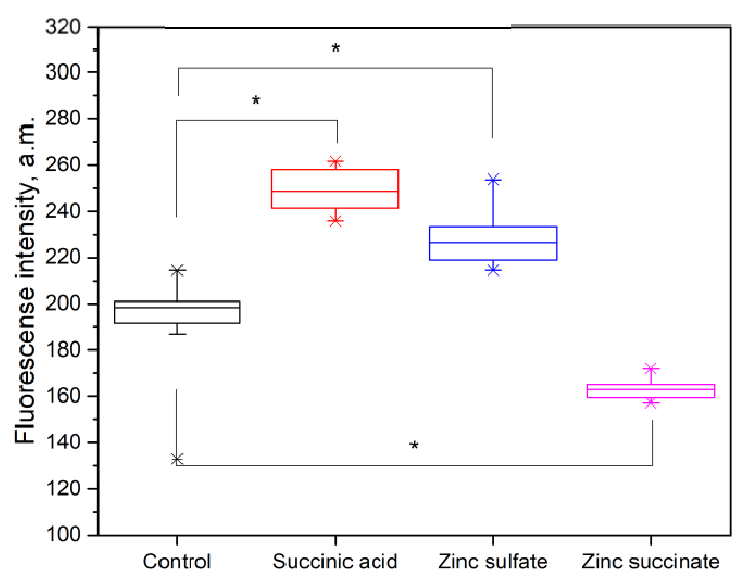

(a)

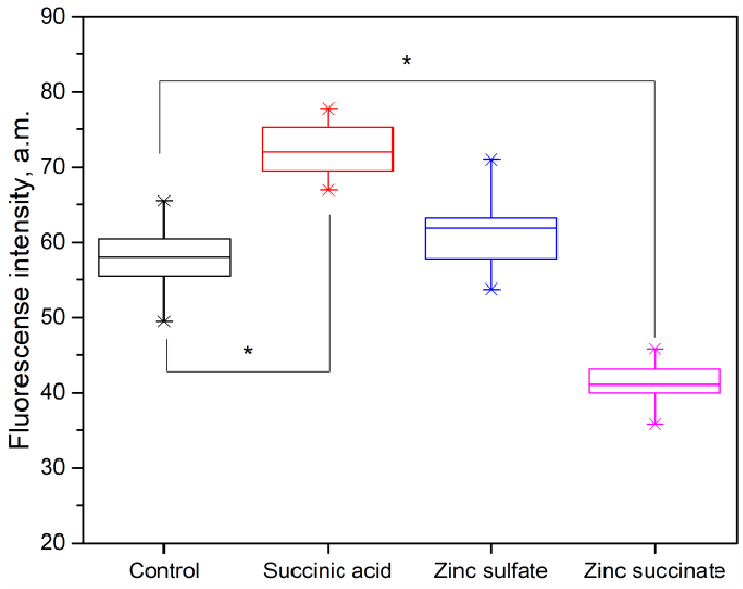

(b)

* - Confirmed the statistical significance of differences in the Mann-Whitney test $(\mathrm{p}<0.05)$

Figure 2- the motor cortex on the wavelength $365 \mathrm{~nm}$ (a) and $450 \mathrm{~nm}$ (b)

When zinc sulphate and succinic acid were introduced into the drinking water separately at a wavelength of $365 \mathrm{~nm}$, an increase in fluorescence intensity was observed in the region of the motor cortex of the brain, which corresponds to the fluorescence of NADH (fig 2). When zinc succinate is used, the intensity at $365 \mathrm{~nm}$ decreases noticeably. At $450 \mathrm{~nm}$, an increase in fluorescence intensity for groups 2 and 3 was observed. For group 4, which received zinc succinate, there is also a noticeable sharp decrease in the fluorescence intensity of FAD. 


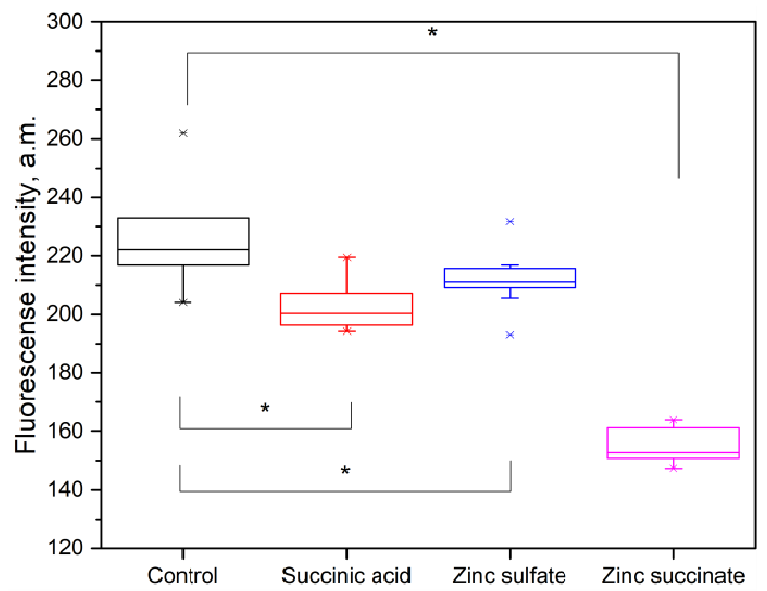

(a)

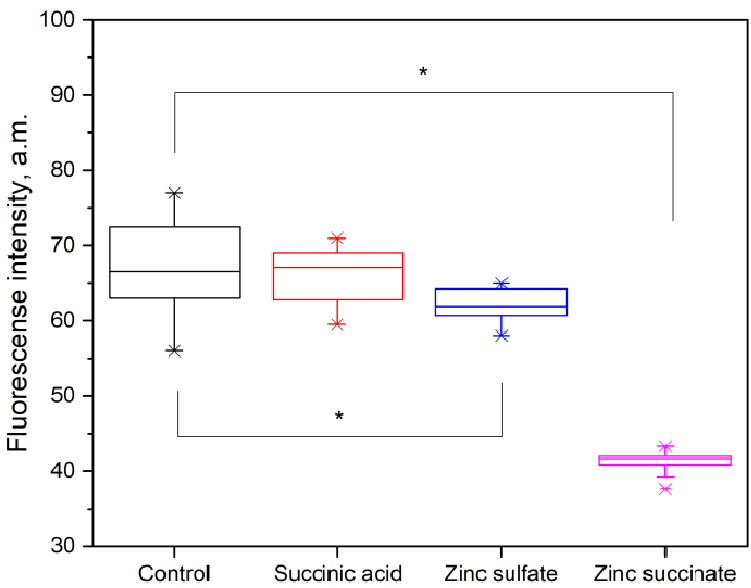

(b)

* - Confirmed the statistical significance of differences in the Mann-Whitney test $(\mathrm{p}<0.05)$

Figure 3 - the visual cortex on the wavelength $365 \mathrm{~nm}$ (a) and $450 \mathrm{~nm}$ (b)

In the visual cortex of the brain (fig 3) at a wavelength of $365 \mathrm{~nm}$ with the consumption of succinic acid, the fluorescence intensity decreased compared to the control group. When measuring at $450 \mathrm{~nm}$, an increase in fluorescence intensity was recorded, which corresponds to a decrease in NADH concentration and FAD growth. Perhaps this is due to the influence of succinic acid on the mitochondrial complex of the II respiration cycle. ${ }^{16}$

Presumably, an increase in the intensity of NADH fluorescence ${ }^{17}$ corresponds to a worsening of oxygen exchange and cellular respiration in the motor and visual regions of the cerebral cortex for groups 2 and 3. On the contrary, for group 4, there is a sharp decrease in the fluorescence intensity of coenzymes NADH and FAD simultaneously in selected regions ${ }^{18,19}$. However, when the zinc succinate complex is used, a fluorescence intensity drop at all wavelengths is observed.

Perhaps succinic acid enhances the toxic effect of zinc, and it leads to the suppression of metabolic processes in the brain tissues. By some indications, this reaction is the initial stage of apoptosis of cells. The accumulation of intracellular $\mathrm{Zn} 2+$ contributes to damage to neurons in certain areas of the brain, including the cortical zones. Excess of zinc is loaded into the mitochondria and leads to its dysfunction. It can be assumed that the main negative effect on neurons due to the accumulation of zinc will be localised in the mitochondria ${ }^{20}$. The $\mathrm{Zn} 2+$ ion can cause deep mitochondrial dysfunction and provoke depolarization of mitochondria and formation of reactive oxygen species (ROS) ${ }^{21}$.

\section{CONCLUSION}

Thus, based on data obtained by fluorescence spectroscopy, we can assume a change in the degree of cellular respiration in different structures of the cerebral cortex with the toxic effect of zinc compounds and succinic acid on the oxygen exchange process. With the use of succinic acid, the change in metabolic processes was presumably associated with an increase in the concentration of coenzymes FAD compared to the control group, which indicates the activation of metabolic processes.

The use of zinc leads to changes in the brain tissues with an increase in coenzymes NADH also a decrease in motor function. Zinc contributes to the death of neurons, because it affects several systems. The excess of zinc can cause deep mitochondrial dysfunction. It can also provoke the depolarisation of mitochondria and the formation of reactive oxygen species (ROS).

Moreover, the introduction of a zinc succinate compound into the rat organism, presumably, could lead to profound metabolic dysfunctions and impaired cellular respiration in brain cells. These changes were recorded by fluorescence spectroscopy in the areas of cerebral cortex of Wistar rats. The results of this work can be used in researches of neuronal death related to major neurological disorders in humans, including stroke, epilepsy and Alzheimer's disease. 


\section{ACKNOWLEDGEMENTS}

The work was funded by RFBR according to the research project №18-02-00669. Dr Evgeny Zherebtsov kindly acknowledges funding from the European Union's Horizon 2020 research and innovation programme under the Marie Skłodowska-Curie grant agreement No. 703145.

\section{REFERENCES}

[1] Istrate, A. N., Kozin, S. A., Zhokhov, S. S., Mantsyzov, A. B., Kechko, O. I., Pastore, A., Makarov, A. A. and Polshakov, V. I., "Interplay of histidine residues of the Alzheimer's disease A $\beta$ peptide governs its Zn-induced oligomerization," Sci. Rep. 6, 21734 (2016).

[2] Kozin, S. A., Zirah, S., Rebuffat, S., Hoa, G. H. and Debey, P., "Zinc binding to Alzheimer's Abeta(1-16) peptide results in stable soluble complex.," Biochem. Biophys. Res. Commun. 285(4), 959-964 (2001).

[3] Lemire, J., Mailloux, R. and Appanna, V. D., "Zinc toxicity alters mitochondrial metabolism and leads to decreased ATP production in hepatocytes," J Appl Toxicol 28(2), 2007/06/22, 175-182 (2008).

[4] Safonova, O. A., Popova, T. N., Slivkin, A. I. and Talmi, Y., "Effects of a Preparation Containing Pantogam, Succinic Acid, and Chitosan on Activities of the Glutathione System and NADPH-Generating Enzymes in Rat Tissues under Conditions of Cerebral Ischemia/Reperfusion.," Bull. Exp. Biol. Med. 159(2), 221-224 (2015).

[5] Yamaguchi, M., Kura, M. and Okada, S., "Role of zinc as an activator of mitochondrial function in rat liver," Biochem Pharmacol 31(7), 1982/04/01, 1289-1293 (1982).

[6] Hillman, E. M. C., "Optical brain imaging in vivo: techniques and applications from animal to man,” J. Biomed. Opt. 12(5), 51402 (2007).

[7] Stelmashchuk, O., Zherebtsov, E., Zherebtsova, A., Kuznetsova, E., Vinokurov, A., Dunaev, A., Mamoshin, A., Snimshchikova, I., Borsukov, A., Bykov, A. and Meglinski, I., "Noninvasive control of the transport function of fluorescent coloured liposomal nanoparticles," Laser Phys. Lett. 14(6) (2017).

[8] Lee, S. C., Han, J. Y., Chun, I. K., Lee, S. Y. and Cho, M. H., "Distributed image reconstruction for an in-vivo mouse imaging system," Med. Imaging 2003 5030, 8, SPIE (2003).

[9] Valery Tuchin., [Tissue optics : light scattering methods and i nstruments f or medical diagnosis] (2015).

[10] Dunaev, A. V, Dremin, V. V, Zherebtsov, E. A., Rafailov, I. E., Litvinova, K. S., Palmer, S. G., Stewart, N. A., Sokolovski, S. G. and Rafailov, E. U., "Individual variability analysis of fluorescence parameters measured in skin with different levels of nutritive blood flow," Med Eng Phys 37(6), 2015/04/30, 574-583 (2015).

[11] Stelmashchuk, O., Zherebtsov, E., Zherebtsova, A., Kuznetsova, E., Vinokurov, A., Dunaev, A., Mamoshin, A., Snimshchikova, I., Borsukov, A., Bykov, A. and Meglinski, I., "Non-invasive control of influence of polyethylene glycol on transport function of fluorescent colored liposomal nanoparticles," Prog. Biomed. Opt. Imaging - Proc. SPIE 10336 (2017).

[12] P'yavchenko, G. A., Shmarkova, L. I. and Nozdrin, V. I., "Changes in the Number of Neurons in the Rat Motor Cortex and Movement Activity with Age," Neurosci. Behav. Physiol. 46(3), 270-273 (2016).

[13] Akbar, N., Sokolovski, S., Dunaev, A., Belch, J. J. F., Rafailov, E. and Khan, F., "In vivo noninvasive 
measurement of skin autofluorescence biomarkers relate to cardiovascular disease in mice," J. Microsc. 255(1), 42-48 (2014).

[14] Palmer, S., Litvinova, K., Dunaev, A., Fleming, S., McGloin, D. and Nabi, G., "Changes in autofluorescence based organoid model of muscle invasive urinary bladder cancer,” Biomed. Opt. Express 7(4), 1193 (2016).

[15] Paxinos, G. and Watson, C., "The Rat Brain in Stereotaxic Coordinates Sixth Edition," Elsevier Acad. Press 170, 547-612 (2007).

[16] Tretter, L., Patocs, A. and Chinopoulos, C., "Succinate, an intermediate in metabolism, signal transduction, ROS, hypoxia, and tumorigenesis," Biochim. Biophys. Acta - Bioenerg. 1857(8), 1086-1101 (2016).

[17] Mayevsky, A. and Chance, B., "Oxidation-reduction states of NADH in vivo: From animals to clinical use," Mitochondrion 7(5), 330-339 (2007).

[18] Mokrý, M., Gál, P., Harakal'ová, M., Hutňanová, Ž. `, Kušnír, J., Mozeš, Š. `a and Sabo, J., "Experimental study on predicting skin flap necrosis by fluorescence in the FAD and NADH bands during surgery," Photochem. Photobiol. 83(5), 1193-1196 (2007).

[19] Wang, H.-W., Wei, Y.-H. and Guo, H.-W., "Reduced Nicotinamide Adenine Dinucleotide (NADH) Fluorescence for the Detection of Cell Death,” Anticancer. Agents Med. Chem. 9(9), 1012-1017 (2009).

[20] Sensi, S. L., Ton-That, D., Sullivan, P. G., Jonas, E. A., Gee, K. R., Kaczmarek, L. K. and Weiss, J. H., "Modulation of mitochondrial function by endogenous $\mathrm{Zn}(2+)$ pools," Proc. Natl. Acad. Sci. U. S. A. 100(10), 6157-6162 (2003).

[21] Sensi, S. L., Paoletti, P., Koh, J.-Y., Aizenman, E., Bush, A. I. and Hershfinkel, M., "The Neurophysiology and Pathology of Brain Zinc,” J. Neurosci. 31(45), 16076 LP-16085 (2011). 